\title{
DÜBLIN
}

Technological University Dublin

ARROW@TU Dublin

\section{Current Perspectives on Violence Against Children in Europe}

\author{
Kevin Lalor \\ Technological University Dublin, kevin.lalor@tudublin.ie \\ Rosaleen McElvaney \\ Dublin City University, rosaleen.mcelvaney@dcu.ie
}

Follow this and additional works at: https://arrow.tudublin.ie/aaschsslbk

Part of the Other International and Area Studies Commons

\section{Recommended Citation}

Lalor, K., \& McElvaney, R. (2018). Current perspectives on violence against children in Europe. In G. Lenzer (ed.), Violence against children: Making human rights real. New York: Routledge.

This Book Chapter is brought to you for free and open access by the Social Sciences at ARROW@TU Dublin. It has been accepted for inclusion in Books/Book chapters by an authorized administrator of ARROW@TU Dublin.

For more information, please contact arrow.admin@tudublin.ie, aisling.coyne@tudublin.ie, gerard.connolly@tudublin.ie.

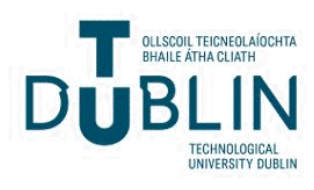




\title{
8
}

\section{Current Perspectives on Violence Against Children in Europe}

\author{
Kevin Lalor and Rosaleen McElvaney
}

\section{Introduction}

The Council of Europe Strategy for the Rights of the Child (2016-2021) (www.coe.org) was designed to address key challenges facing children's rights in today’s world, such as inequality, a justice system designed for adults, racism, growing up in a digital world and migration. The priority areas therefore focus on equal opportunities for all children, child participation, a life free from violence, a child-friendly justice system and promoting the rights of the child in a digital environment. The Council of Europe continues its commitment to the four principles of the United Nations Convention on the Rights of the Child (UNCRC): non-discrimination (Article 2), the best interests of the child (Article 3), children's right to life, survival and development, including a life free from violence (Article 6) and the right to be heard (Article 12). The strategy will be delivered by continuing the work of implementing existing standards in collaboration with all key stakeholders, in particular raising awareness of children's rights through communication and ongoing evaluation of the strategy. Children will continue to be consulted in this ongoing evaluation process. In this chapter we will focus in particular on priority area 3 (A life free from violence for all children) and priority area 5 (Rights of the child in a digital environment). We will provide a brief overview of current prevalence rates of child maltreatment across Europe drawing on recent metanalytic studies 
and systematic reviews. The chapter will outline recent and ongoing policy and strategic initiatives, including initiatives by the European Society of Children’s

Ombudsmans/Children’s Commissioners. Current challenges facing children’s rights in Europe will be discussed, including sexual exploitation, online risks, corporal punishment and migration.

\section{Prevalence}

Few individual countries systematically collect prevalence data on violence against children. Even fewer groups of countries collect data on violence against children using common definitions, methodologies and research instruments. Consequently, it is not possible to quantify accurately the levels of violence and abuse experienced by children across Europe.

The World Health Organization Regional Office for Europe’s (Sethi et al., 2013) "European report on preventing child maltreatment” summarised the findings of surveys from Europe and around the world, and suggested a prevalence rate of $9.6 \%$ for sexual abuse of children (13.4\% in girls and 5.7\% in boys), $22.9 \%$ for physical abuse and $29.1 \%$ for mental abuse. By applying these rates to the child population of Europe, it is suggested that "18 million children suffer from sexual abuse, 44 million from physical abuse and 55 million from mental abuse” (p. viii). These figures are "best guess” approximations, but they do give an indication of the scale of violence against children in Europe. Until countries systematically measure such experiences, it is not possible to be more accurate.

Nevertheless, community surveys have been conducted in most European countries, most frequently on the sexual abuse of children. We have previously summarised the findings of meta-reviews and prevalence studies across Europe (McElvaney \& Lalor, 2014).

Reflecting differences in research design, methodology and sampling, prevalence rates vary 
widely. For example, prevalence rates for sexual abuse of boys have been reported as low as $0.6 \%$ in France and as high as $13.4 \%$ in Spain, whereas for girls they were as low as $0.9 \%$ in France and as high as $28.1 \%$ in Sweden. A review of the prevalence rate of child sexual abuse (broadly defined) in the Nordic countries (Kloppin, Haugland, Svedin, Maehle, \& Breivik, 2016) suggested a prevalence rate of between 3-23\% for boys and 11-36\% for girls. Rates for contact abuse were between 1-12\% for boys and 6-30\% for girls. Rates for penetrative abuse were between $0.3-6.8 \%$ for boys and $1.1-13.5 \%$ for girls. Prevoo, Stoltenborgh, Alink, Bakermans-Kranenburg, \& Ijzendoorn (2016), in their review of four meta-analyses on child maltreatment, suggest that methodological differences partly explain the wide range of lifetime prevalence rates.

The BECAN study (Balkan Epidemiological Study on Child Abuse and Neglect) is very significant as it used common measures and methodologies to study child abuse and neglect in nine Balkan countries. Between 2009-2012 the project surveyed the prevalence of child abuse among representative randomized samples of 11 to 16 year olds in Albania, Bosnia and Herzegovina, Bulgaria, Croatia, F.Y.R. of Macedonia, Greece, Romania, Serbia and Turkey. The research instrument was the ICAST (ISPCAN Child Abuse Screening Tool) questionnaire, created by ISPCAN/UNICEF (International Society for the Prevention of Child Abuse and Neglect / United Nations Children's Fund) and recommended by the World Health Organization. In total, 42,272 questionnaires were collected from school-going children across the nine countries. High levels of psychological violence were reported. Between $65 \%$ and $83 \%$ of respondents reported experiencing at least one psychologically violent act during their life time; and between 60-70\% had experienced psychological violence during the past 12 months. High levels of physical violence were also reported, ranging from $51 \%$ to $76 \%$ for children's life time and from $42 \%$ to $51 \%$ for the past year. For 
sexual violence, rates from $8 \%$ to $19 \%$ "for children's life time" and from $5 \%$ to $14 \%$ "for the past year” were reported (European Commission, Community Research and Development Information Service, 2013).

Notwithstanding the methodological difficulties inherent in such studies, the extensive research that has been conducted across the region is unequivocal that the sexual, physical and emotional maltreatment of children occurs in all populations, and it is at least as prevalent in Europe as it is in other regions around the world.

\section{Children's Rights and the Ombudspersons of Europe}

The European Network of Ombudspersons for Children (ENOC) is a network of independent children's rights associations across Europe whose brief is to promote implementation of the United Nations Convention on the Rights of the Child (UNCRC). Established in 1997, it has grown to represent 34 of the 47 Member States of the Council of Europe.

Despite the commitment of the UNCRC to the right of every child to grow up without violence (Article 19), this is not the reality for millions of children across Europe (Sethi et al., 2013). ENOC expresses the view that while the legal basis for taking measures to tackle all violence against children is already there, implementation of these measures is poor.

In a position statement in September 2015, ENOC (2015) called on governments, the European Commission and the Council of Europe to take a stand against violence towards children and implement the following recommendations. 
1. A full ban on corporal punishment (over $30 \%$ of EU countries do not have a full ban on corporal punishment, while a further third have a ban that is not fully implemented).

2. Introduction of high quality identification and reporting procedures that facilitates children in disclosing experiences of violence and ensures that professionals detect and report such violation of children's rights.

3. Educating children about violence and their rights, and mandatory training for professionals in identifying and reporting violence against children.

4. Developing sufficient protection for known victims, including researching established effective protection measures for the safety and well-being of maltreated children.

5. Training of all professionals who come into contact with children following reporting, through child protection, therapeutic and legal systems to ensure that children are not re-victimised.

6. Strengthening the child protection and welfare system in responding to maltreated children, in particular for those children who have additional vulnerabilities such as minority, disabled children, LGBT children, children in armed conflict and children on the move.

7. Promoting children's right to be heard through mandating systems to seek the views of children as they progress through the child protection and welfare systems.

8. Finally, embedding the above measures into a national strategy to combat violence against children. 
The ENOC acknowledges that national governments are the designated bodies to safeguard the well-being of children but calls on the European Commission and the European Parliament to support, facilitate and accelerate these developments and in particular to take responsibility for data collection, research and training of professionals.

A consultation process with the European Network of Young Advisors (ENYA) “Let’s talk young, Let’s talk about violence” project (see http://enoc.eu/?page_id=479) coordinated by ENOC highlighted the views of young people that governments were not doing enough to address: the impact of a consumer-based economy on child poverty; "so-called differences” between people based on race, religion, disability or gender; the impact of mass media that represents children as a threat to society; and the need for parents and professionals to access training in how to listen to children, understand them, and take action to protect them (ENOC, 2015). These views are echoed in another desktop review conducted by the Council of Europe (2016) in preparation for the 2016-2021 Strategy for the Rights of the Child. Their findings suggested that: a) children in Europe wish to be heard and have more influence on decisions made regarding their rights; b) children look more to friends and family than to professionals for information they need; and c) children are only too aware of the impact of recent economic recessions and the need for more resources to provide adequate protection of their rights, in particular the need for well trained professionals.

In collaboration with young people, the Ombudspersons of Europe continues to be an important lobby group in advocating for the rights of children in Europe. Particular challenges to those rights include the need to address child sexual exploitation.

\section{Combating Child Sexual Exploitation}


In this section we describe European strategies to combat child sexual exploitation. First, we describe the provisions and implementation of the 2011 EU Directive on "Combating the sexual abuse and sexual exploitation of children and child pornography”. This is followed by a focus in particular on the issue of online sexual exploitation.

The 2004 EU Framework Decision on combating the sexual exploitation of children and child pornography was designed to bring a coordinated, consistent approach across Member States. It sought to introduce “common provisions to regulate the creation of sexual exploitation offences, penalties, aggravating circumstances, jurisdiction and extradition. The Framework Decision also called for the sensitive treatment and protection of child victims in the investigation and prosecution of such offences” (Stalford, 2012, p. 174). After the Lisbon Treaty, in 2011, the Framework Decision was transposed into a Directive (2011/93/EU) with new provisions "to address the impact of technological developments on child sexual exploitation” (p. 174).

The Directive provides a legal framework for Member States to prevent, investigate and prosecute sexual crimes against children and assist and protect victims. It defines a range of offences (including online grooming; webcam sexual abuse; and the viewing without downloading of child abuse material); while setting minimum levels of criminal penalties and facilitates reporting, investigation and prosecution. It also enables the prosecution of EU citizens for offences which occurred in other EU countries, or in non-EU countries; and it prohibits the organisation of child sex tourism.

The Directive also mandates a range of support and protection services for child victims, with a particular emphasis on reducing secondary trauma by setting specific standards for interviews with child victims. Finally, the Directive mandates a range of measures to prevent these crimes, including "Mechanisms to enable excluding convicted 
offenders from professional activities involving direct and regular contact with children”; "The right of employers to request information about convictions and disqualifications for professional or organised voluntary activities involving direct and regular contact with children”; “A requirement that Member States make intervention programmes or measures such as treatment available to convicted offenders and others who fear they could offend”; and “An obligation on Member States to carry out prevention activities such as education, awareness raising and training of officials” (European Commission, 2016b).

The Directive was to be transposed into national laws by December 2013. However, by that date, only 12 Member States had notified the Commission that they had completed transposition of the Directive (the remaining countries completed transposition by December 2016).

In December 2016, two reports were made to the Commission on the steps taken by Member States to combat the sexual abuse and sexual exploitation of children and child pornography.

One is focused on websites containing child abuse material (termed "child pornography” in the legislation) (European Commission, 2016a) and the other addresses more broadly all the provisions in the Directive (European Commission, 2016b). We shall examine both in turn below.

Article 25 of the EU Directive Combating the Sexual Abuse and Sexual Exploitation of Children and Child Pornography requires Member States (1) to remove webpages containing child pornography hosted in their jurisdiction, and (2) to endeavour "to obtain the removal of such pages hosted outside of their territory”. The Directive also provides a provision for Member States to block access to webpages hosted in their jurisdiction that 
contain child pornography (subject to a number of safeguards, including that such moves are transparent and proportionate).

There is a comprehensive "notice and take down” procedure to tackle child pornography across the EU. There are 51 Hotlines in 45 countries, where internet users can report webpages with suspected child sexual abuse material. Generally speaking, the Hotline will determine the host country based on the URL, it will analyze the material to determine if it is illegal and, if so, report it to the Law Enforcement Agency (LEA) of that country. Various protocols exist in different member states, but, overall, the hosting provider will be informed by the LEA and/or the hotline, so the material can be removed or "be held liable if it fails to remove it in accordance with the national implementing laws” (European Commission, 2016a, p. 8). Protocols vary from country to country and include provisions that material be removed “without undue delay” (Czech Republic), “executed immediately” (Greece), and “within 12 hours” (Hungary). Statistics generated by INHOPE (the umbrella organisation for Hotlines across Europe) and cited by the European Commission, 2016a) suggest that $93 \%$ of the child sexual abuse material processed by the hotlines in Europe, and 91\% of the material processed by the Hotlines worldwide, was removed from Internet public access in less than 72 hours.

According to the European Commission, 2016a), 14 Member States currently apply blocking measures. In some countries, a court order is required to block a website; in others, Internet Service Providers (ISPs) are required by law to comply with a request by the authorities to block a webpage; and in others, ISPs are not explicitly obliged by law to comply with a request from the LEA, but do so anyway. The information from Member States submitted to the Commission on which this report is based, did not conclusively detail the number of webpages blocked, or the number of attempts blocked. 
The general conclusion of the report is that significant efforts have been made by Member States to remove and block webpages that contain and disseminate child abuse material.

The second report to the Commission on the steps taken by Member States to respond to the Directive (European Commission, 2016b) looked more broadly at the range of provisions contained in the Directive. The report acknowledges that transposing such a wide ranging Directive into national legislation is an enormous undertaking. It requires legislative changes in criminal law including definitions of offences, levels of penalties, statutes of limitations and the liability of legal persons along with changes in procedural criminal law relating to extraterritorial jurisdiction, the participation of children in criminal proceedings and legal representation (European Commission, 2016b). It entails extensive administrative measures to accompany the legislation and collaboration between national and regional governments and non-governmental organisations, for example in awareness raising campaigns. It requires the cooperation of internet service providers, for example to disrupt the distribution of child sexual abuse material, and clinical psychologists in the provision of intervention programmes for offenders, among other key actors. More than 300 new pieces of legislation relating to the Directive across all Member States have been communicated to the Commission.

The report details the extent to which each article of the Directive has been transposed into national legislation in each Member State. Not surprisingly, there is considerable variation in implementation and terminology used in legislation. In many instances, the report observes that the information supplied by Member States to the Commission was not conclusive. 
Overall, the report concludes that Member States have made considerable progress in amending criminal codes, streamlining procedures and transposing the provisions of the Directive into national legislation. However, there is room for further work. This is particularly true with regard to prevention and intervention programmes for offenders. For example:

- $\quad$ Article 22 requires Member States to ensure that potential perpetrators, those who fear that they may offend, have access to programmes or measures that are designed to prevent the risk of offending. Such measures have been put in place only in seven countries (Austria, Bulgaria, Denmark, Finland, Netherlands, Slovakia and the UK).

- $\quad$ Article 24(1) requires Member States to ensure that effective intervention programmes or measures are provided throughout the criminal proceedings, to minimise the risks of re-offending. The report noted that "a number" of Member States have taken steps to transpose this provision, but that the information provided by the vast majority (19 countries) was not conclusive.

\section{Understanding Online Risks and Opportunities}

While EU directives address violence against children at European and governmental levels, there is an urgent need to engage in ongoing research to develop knowledge and understanding of the challenges facing children so that innovative initiatives can be taken to help children and families.

While all violence against children needs continuous attention, technological developments in the last 20 years have brought new challenges for practitioners, policymakers and governments striving to protect children. These developments have expanded 
children's horizons and allowed them access to new educational and recreational possibilities. However, they have also provided a platform for the abuse of children, both by adults and by peers. Considerable efforts have been expended in recent years in Europe to help us better understand these phenomena and develop better mechanisms to protect children from harm.

Bullying has become a major epidemic in many countries across the Globe. A recent study, drawing on prevalence studies conducted across 79 countries in Africa (14), America (18), Southeast Asia (6), Europe (34) and the Eastern Mediterranean (7) found that $32.4 \%$ of adolescent males and $27.6 \%$ of adolescent females aged 11 to 16 years reported bullying victimization (Elgar et al., 2015). The study focused on the relationship between country wealth and prevalence of bullying. They found that violence was directly related to country wealth—-the more wealthy the country, the lower the prevalence of bullying. Moderating variables for this relationship were education spending and income inequality.

A form of bullying that has become more prevalent with the increased availability and usage of digital technology is cyber bullying (Völlink, Dehue, \& McGuckin, 2016). Cyber victimization is considered to be less prevalent than traditional bullying, with considerable overlap between the two types of victimization (Sjursø, Fandrum, \& Roland, 2016). Recent research suggests that there may be a differential impact between offline and online bullying with depression being more associated with traditional bullying and anxiety more prevalent among those experiencing cyber victimisation (Sjursø et al., 2016). Some features of cyber bullying (such as the anonymity of the person who bullies, and the public nature of some cyber bullying, where the written comments may be published to a large audience (Menesini, Nocentini, \& Camodeca, 2013) may contribute to the victim’s vulnerability in developing anxiety symptoms. Sjursø and colleagues point out that young people may need to be taught different coping skills and need different types of support, depending on the form of bullying. 
Increased use of mobile technology and access to the internet has opened up new vulnerabilities for children and young people and provided those who would exploit these vulnerabilities with new, and some would argue, easier methods of exploitation. Studies in Europe have highlighted the prevalence of various forms of sexual behaviour online. The EU Kids Online study draws on in-home face-to-face interviews with 25,000 European 9- to 16year-old internet users and their parents in 25 countries in 2010 (see http://eprints.lse.ac.uk/33731/). The Net Children Go Mobile survey built on the EU Kids Online study and focused on mobile devices, with 3,500 European 9- to16-year-old internet users in seven countries in 2013/14 (see www.netchildrengomobile.eu/ reports). According to Livingstone, Mascheroni, Ólafsson, and Haddon (2014), approximately half of all 11- to16year-olds had encountered one or more of 10 risks asked about. Such risks ranged from viewing inappropriate websites promoting risky behaviour (self-harm or harm to others) or online sexual images, experiencing cyberbullying, meeting online contacts offline, or receiving sexual messages.

In other studies, young people have reported being asked sexually inappropriate questions online and meeting adult offenders in Internet chat rooms, being groomed and lured into a sexual relationship with a man who pretended to be a woman online (Quayle \& Sinclair, 2012). One behaviour that has raised concern is that of "sexting” whereby young people upload sexual images of themselves and share with others. In particular, concerns arise when such images are shared without the sender's consent. Cooper, Quayle, Jonsson, and Svedin (2016) conducted a review of the literature on sexting to better understand young people's behaviour and motivations for sexting. Their review suggests that despite the above concerns, for the most part sexting takes place in the context of either a romantic relationship or as a means of exploring sexuality and identity. This finding is consistent with research 
from the U.S. conducted by Wolak and Finkelhor (2011), who described sexting as emanating from typical adolescent flirting behaviour.

The European NGO Alliance for Child Safety Online (eNACSO) was established in 2008 by the European Commission. It currently has 28 members from across Europe. Its mission is based on the 1989 UN Convention on the Rights of the Child (UNCRC) and aims to "promote and support actions at national, European and international level, to protect children and promote their rights in relation to new media” (www.enacso.eu). The Alliance commissioned a desktop literature review from Livingstone and Mason (2015) to examine the risks and opportunities that 10- to 17-year-olds face online when seeking or encountering sexual information. Despite the focus of most research on online risk rather than opportunity, the review sheds some light on current knowledge of young people's online behaviour and is summarized below.

Research suggests a relationship between online and offline risk: adolescents who are vulnerable offline tend to be vulnerable online and vice versa. The risk factors identified include older age, risk-taking tendencies, poor family or peer relationships, low self-esteem and poor body image. Older children are more likely to use the internet to access sexual content and take risks online; the 9-12 age range is suggested as an important age for beginning risky online behaviour.

The dynamics that influence when children and young people use information communication technologies (ICTs) for sexual purposes include: unequal gender dynamics, gendered pressure on sexual behaviour, low levels of knowledge or discussion among peers in school or with parents of the issue of consent. Online access to information about sexual health was seen as important to all youth but particularly to those with low income, LGBT and homeless youth. The authors note that more information is needed about the type of 
information young people want, the roles that parents, schools and web resources could play in informing young people and the trust that young people place in these various sources of information.

A considerable number of children and young people (more boys than girls) are exposed to or access pornography online and the impact appears to vary according to gender (Livingstone \& Mason, 2015). Exposure to pornography has been found to impact negatively on young people's sexual attitudes, expectations and beliefs as well as their health and well being. Girls are under more pressure to engage in "sexting” or sharing self-generated explicit images and are also subject to more harsh judgment when these images are shared in a wider group. Older youth and those who engage in risk taking or sensation seeking behaviour are more likely to engage in this behaviour. Information on children’s conceptual understanding of consent, their knowledge levels and understanding of "sexting” is lacking.

Girls are more vulnerable to sexual solicitation online and to be impacted negatively by this. However, they are also more likely to seek help or advice from an adult when this occurs. ICTs are being used for grooming purposes. Vulnerable young people such as those with a lack of parental involvement, previous experience of sexual abuse or engagement in risk-taking behaviour are less able to protect themselves from online grooming.

The report emphasizes the importance of upholding children's rights to engage with the internet and the opportunities it provides as well as their right to protection from harm: "the difficult balance must be found between providing opportunities online to underpin young people’s right to sexual information and participation, and ensuring their protection from online sexual harm” (Livingstone \& Mason, 2015, p. 48). The authors’ recommendations include the need for explicit attention to both safety and children's rights to information, expression and participation; involving adolescents in research to better 
understand their needs, their interests and their views on education programmes and policy developments; introducing sex and relationship education into the school curricula that covers emotions, consent, sexual identity, healthy and unhealthy relationships, sources of trustworthy information, and how to use media tools and critically understand and evaluate content such as pornography, sexual and reproductive health issues from an early age; supporting parents with educational materials; ensuring that policy and practice is based on high quality research; and evaluating interventions and educational approaches to identify how best to support parents in supporting their children.

In particular, the report calls on the need for extensive qualitative research that could capture young people’s views and experiences to better inform policy development and interventions. Some examples of such research can be found in the ROBERT project (Risktaking Online Behaviour Empowerment through Research and Training). The project is a collaboration between Estonia, Sweden, UK, Denmark, Italy, Germany, the Netherlands and Russia, with co-operation from a range of other European countries and funded by the European Commission Safer Internet Programme (see www.childcentre.info/robert/aboutthe-project/)for reports drawing on interviews with online sex offenders (Quayle, Allegro, Hutton, Sheath, \& Lööf, 2012) and with affected young people (Quayle, Jonsson, \& Lööf, 2012).

As Quayle and Sinclair (2012) point out, outside of educating children about the dangers of generating content about themselves or 'sexting', little has been written about how to help children protect themselves or how adults can help protect children in relation to abusive images. Industry has played some role by entering into agreements to block websites or content (Eneman, 2010), and as noted above, the EU has shown initiative in the form of the 2011 Directive on "Combating the sexual abuse and sexual exploitation of children and 
child pornography” discussed above, but clearly, this is an area in need of more focus and action.

Nevertheless, The PSHE (Personal, Social, Health and Economic education, 2016) Association in the UK, in reviewing the evidence base for prevention programmes in general, identified the key components of effective prevention programmes that may be helpful in combating online sexual exploitation. These include: a focus on a developmental approach that takes account of the age of the child and their particular context, active learning strategies that focus on skill-building and convey content that draws on well established knowledge of the behaviours, skills and attributes associated with risky and safe online behaviour; involvement of key stakeholders including pupils, parents, teachers and the broader community; clear objectives and ongoing evaluation; and clarity on intended outcomes and ongoing evaluation of these.

While online exploitation has captured the attention of service providers and policymakers across Europe, an additional issue, corporal punishment, is worthy of mention here with regard to developments across the continent before we move to discuss another key challenge facing European children today_that of migration.

\section{Corporal Punishment}

Until relatively recently, corporal punishment of children was widely practiced throughout Europe in homes, schools and other settings. A very early initiative to ban corporal punishment started in Sweden, which became the first country in Europe (and the World) to ban corporal punishment in 1979. This led to a marked decline in acceptance of this form of punishment. Importantly, the ban was accompanied by a massive public education campaign 
about the effects of corporal punishment, and alternative forms of punishment (Ziegert, 1983).

Perhaps the most comprehensive sources of information about corporal punishment in Europe (and worldwide) are the annual reports issued by the NGO Global Initiative to End All Corporal Punishment of Children. Its most recent report shows that at the end of 2016, 51 countries across the world have prohibited all corporal punishment, including in the home. A further 55 countries have committed to such a ban and legislation is at various stages of preparation.

The European countries (defined as members of the Council of Europe) that have prohibited corporal punishment in all settings are: Albania, Andorra, Austria, Bulgaria, Croatia, Cyprus, Denmark, Estonia, Finland, Germany, Greece, Hungary, Iceland, Ireland, Latvia, Liechtenstein, Luxembourg, Malta, Netherlands, Norway, Poland, Portugal, Republic of Moldova, Romania, San Marino, Slovenia, Spain, Sweden, TFYR Macedonia and the Ukraine. The European countries committed to prohibition are: Bosnia and Herzegovina, Lithuania, Montenegro, Serbia and Slovakia.

At the time of writing, the following Member States of the Council of Europe have not prohibited corporal punishment in all settings, or committed to enacting legislation to bring this about: Armenia, Azerbaijan, Belgium, France, Georgia, Italy, Monaco, Czech Republic, United Kingdom, Russia, Saint Marino, Switzerland and Turkey. There have been setbacks also. In January 2017, Russia enacted a law which decriminalises domestic violence against women and children, unless it causes serious medical harm (The Economist, 2017).

It is important to note that the UN Committee on the Rights of the Child has recommended that all UN Member States enact a legal prohibition on corporal punishment in all settings. Most recently, General comment No. 20 (2016) on the implementation of the 
rights of the child during adolescence (UN Committee on the Rights of the Child, 2016) “recommends comprehensive legislative, administrative, social and educational measures to bring an end to all forms of violence, including a legal prohibition on corporal punishment in all settings” (para 49). Overall, this represents a significant culture change across Europe. As Paulo Sérgio Pinheiro notes, "We know that prohibition of corporal punishment in law provides the essential foundation for eliminating it in practice” (Global Initiative to End All Corporal Punishment of Children, 2016, p. 2).

The ending of corporal punishment is a key objective for the UN 2030 Agenda for Sustainable Development. Member States must work to “End abuse, exploitation, trafficking and all forms of violence against and torture of children” (target 16.2). One of the three indicators that will be used to measure progress towards this target is the percentage of children under 17 years who have experienced physical punishment and/or psychological aggression by caregivers in the previous month (Target 16.2.1). The adoption of this target by the international community highlights the importance of eliminating corporal punishment in global efforts to tackle violence against children.

In the final part of this chapter, we examine the ongoing migrant crisis in Europe, which has seen unprecedented numbers of children migrate to Europe.

\section{Children and Migration in Europe}

The migration of families and unaccompanied minors to Europe is not a recent development (as evidenced by the 2010 “Action Plan on Unaccompanied Minors” (European Commission, 2010)), but recent years have seen unprecedented numbers of children migrating to Europe. They come from regions devastated by conflict, such as Afghanistan, Syria, Iraq, Libya, Ukraine, Sudan and Somalia; from regions with oppressive regimes such as Eritrea; and from 
regions with meagre economic opportunities, such as Bangladesh, Pakistan, and parts of West and North Africa. Others come from poorer regions in Europe, such as Moldova and Albania, to seek better lives in Western Europe.

Migration, in itself, is not a form of violence against children. However, the associated exploitation and exposure to risks constitutes violence against migrant children at a scale unprecedented in modern European times. A 2016 report by the House of Lords [United Kingdom] European Union Committee describes the current refugee crisis as "the greatest humanitarian challenge to have faced the European Union since its foundation” (p. 3).

The risks faced by migrant children include:

- Drowning: According to the International Organisation for Migration (https://missingmigrants.iom.int/mediterranean), 3,276 people died in the Mediterranean in 2014, 3,777 in 2015 and 5,085 in 2016. It is not known with any certainty how many of these are children. Save the Children (2016) estimates that 600 children died in 2016 alone.

- Sexually transmitted infections: In evidence to the House of Lords European Union Committee (2016), Ms Kirsty McNeill of Save the Children reported that doctors in their Italy programme found that " $50 \%$ of the children they are dealing with have an STI [sexually transmitted infection]. That is evidence of them being sexually exploited in transit” (p. 11).

- $\quad$ Prolonged detention: Overcrowded and squalid reception centres, particularly in 'hotspots' in Greece and Italy, have struggled to cope with the numbers of migrants. Informal settlements or campsites, often without water, sewage or other basic 
services, have become "home" to children for months at a time. Perhaps the most notorious of these is the now dismantled “Calais Jungle”.1

- $\quad$ Violence and hate speech from officials/police (Amnesty International, 2016).

- More generally, children are vulnerable to exploitation, abuse, and violence both en route to Europe, and on arrival. There are numerous instances of forced begging, labour and prostitution involving unaccompanied minors and other children.

\section{Prevalence of Child Migration}

The exact number of children that have migrated to Europe in recent years is not known, but various indicators provide us with a sense of the unprecedented scale of the movement. For example,

- $\quad$ From January to November 2016, 344,603 people arrived by sea (irregularly), of whom $27 \%$ were children, $18 \%$ were women and 55\% were men (UNHCR, 2016).

- $\quad$ The EU statistics agency, Eurostat (2017), estimates that 234,005 applications for asylum were made in the $28 \mathrm{EU}$ countries by unaccompanied minors between 2008 and 2016. Numbers surged from 11,695 in 2008 to 96,465 in 2015. An unknown number of unaccompanied minors do not claim asylum or register with the authorities, thus the true figure of unaccompanied children arriving in Europe is estimated to be far higher.

- A feature of the migration crisis is that large numbers of children register with the authorities, and then simply disappear. In January 2016, Brian Donald, Europol’s Chief of Staff, estimated that 10,000 migrant children have vanished across Europe 
(5,000 in Italy alone), having registered with state authorities. It is feared that many are being targeted by criminal gangs for sexual exploitation or forced labour. It is important to note that they are not all criminally exploited: "Some might have been passed on to family members. We just don't know where they are, what they're doing or whom they are with” (Townsend, 2016).

It has been, and continues to be, a significant challenge for European countries to respond to the migration crisis. The aforementioned report by the House of Lords, "Children in crisis: Unaccompanied migrant children in the EU” (2016) notes that EU Member States face many challenges in responding to the crisis of unaccompanied migrants. They found a general reluctance among Member States to take responsibility, poor/weak implementation of existing measures and a lack of comparable and reliable data.

The report identifies four underlying problems. The first is a "culture of disbelief and suspicion” of unaccompanied migrant children. These children face invasive age tests (such as dental assessment and bone density measurement) of dubious validity, and multiple interviews with various state agencies, including border control, immigration officials and social services. The report describes a pervasive suspicion of young adults seeking to pass themselves off as minors (the vast majority of unaccompanied minors are 16-17-year-old males).

The second underlying problem is the reluctance of Member States to accept responsibility and to share burdens. This is evidenced when states passively allow children to transit a country or when states actively wave them through borders to neighbouring states. The report highlighted the case of Belgium, as reported by the office of the Flemish Children’s Rights Commissioner. Reportedly, the authorities delayed the registration of unaccompanied minors and implicitly encouraged them to seek asylum in other, nearby, 
countries (House of Lords, European Union Committee, 2016). Germany and Sweden are highlighted as notable exceptions to the general tendency for Member States to minimise or avoid dealing with unaccompanied minors.

The third underlying problem is poor implementation of existing law and policy. The EU has a comprehensive range of legislative and policy instruments to standardise the response to asylum seekers (The Common European Asylum System, CEAS). They govern, inter alia, reception conditions, rules about which state should be responsible for examining an asylum application, family reunification and responses to human trafficking. However, while provisions exist in law, a number of agencies (for example, UNHCR, IOM) giving evidence to the House of Lords research team reported weak and variable implementation in practice. With regard to minimum standards at reception centres, the report concludes:

while material reception conditions vary, the conditions faced by unaccompanied migrant children in some Member States lead us to conclude that, collectively, Member States are fundamentally failing to comply with their obligations under EU and international law to receive and protect children in a manner that recognises their specific vulnerability (House of Lords, 2016, p. 44).

The fourth underlying problem follows as a consequence of the first three problems, that is, a loss of trust by unaccompanied children in the officials and procedures designed to assist them. This can lead to non-cooperation and evasion of personnel charged with offering assistance.

Unfortunately, the refugee and migration crisis in Europe is likely to continue for some time, impacting most severely on children and other vulnerable groups. The key recommendations from the House of Lords European Committee Reports are: 
- To better conform to existing provisions to safeguard children, the EU Commission should strengthen the role of European Asylum Support Office (EASO) in monitoring Member States' compliance with the existing legislation, directives and other regulations (the “acquis”, which constitutes the body of European Union Law).

- Strengthen existing protocols under the Reception Conditions Directive to ensure access to minimum levels of legal advice, mental health care and educationobligations which are not being consistently met.

- Urgent action is needed to tackle the issue of missing unaccompanied children, which it views as "the final consequence of the failures and omissions by Member State authorities” (p. 91).

- $\quad$ Adherence to the fundamental principle in international law that children's best interests must be taken into account in any decision that concerns them. To address this, the "Commission should propose amendments to the EU asylum and trafficking acquis to require relevant authorities to undertake and provide evidence of rigorous best interests assessments. Such assessments should be consistent with General Comment 14 of the UN Committee on the Rights of the Child” (p. 91).

The need to respond to the needs of children in migration is recognised by governments across Europe, and a range of measures are being put in place. In 2016 the Commission proposed reforms of the Common European Asylum System to better safeguard children. The measures include "the reinforcement of guardianship systems in Member States, assessment and determination of the best interests of the child, the definition of family, the criteria for obtaining international protection and quicker access to education” (European Commission, 2016c). 
As the migration crisis continues to unfold, provisions for child migrants must be kept under constant review so that European countries meet the minimum obligations to safeguard children under national, European and international law.

\section{Conclusion}

Whilst more can always be done, children's rights and efforts to combat violence against children receive serious attention and considerable resources from Member States of the European Union and, more widely, from Member States of the Council of Europe. EU legislation is under regular review to better safeguard children's rights and research is ongoing to better understand the challenges facing children and how to best respond to these challenges to uphold children's rights to a life free from violence. While it was not a focus of this chapter, European countries are often early signatories of international instruments to safeguard children’s rights. For example, the (2nd) “Optional Protocol to the Convention on the Rights of the Child on the Sale of Children, Child Prostitution and Child Pornography” has been ratified by all Member States of the Council of Europe except Ireland, where ratification is pending following the enactment of the Criminal Law (Sexual Offences) Bill 2015 currently before parliament (see Parliamentary Question and written answer, October 2016, No. $193^{2}$ ).

As a final point, efforts to tackle violence against children of all types in Europe would benefit from better and more systematic collection of data, to raise awareness, inform policy-makers and influence the allocation of resources. 
8 Current Perspectives on Violence Against Children in Europe

\section{References}

Amnesty International. (2016). Hotspot Italy: How EU's flagship approach leads to violations of refugee and migrant rights. Retrieved January 14, 2017 from www.amnesty.org/en/documents/eur30/5004/2016/en/.

Cooper, K., Quayle, E., Jonsson, L., \& Svedin, C. G. (2016). Adolescents and self-taken sexual images: A review of the literature. Computers in Human Behavior, 55, 706716. doi:10.1016/j.chb.2015.10.003.

Council of Europe. (2016). Challenges to children's rights today: What do children think? A desktop study on children's views and priorities to inform the next Council of Europe Strategy for the Rights of the Child. Strasbourg: Council of Europe. Retrieved from https://rm.coe.int/CoERMPublicCommonSearchServices/DisplayDCTMContent?doc umentId=0900001680643ded.

Economist. (2017, January). The Duma's war on women: Why Russia is about to decriminalise wife-beating. The Economist. Retrieved from www.economist.com/news/europe/21715726-it-fits-traditional-values-lawmakers-saywhy-russia-about-decriminalise-wife-beating [accessed 13 February 2017].

Elgar, F. J., McKinnon, B., Walsh, S. D. et al. (2015). Structural determinants of youth bullying and fighting in 79 countries. Journal of Adolescent Health, 57, 643-650.

Eneman, M. (2010). Internet Service Provider (ISP) filtering of child-abusive material: A critical reflection of its effectiveness. Journal of Sexual Aggression, 16(2), 223-235. doi:10.1080/13552601003760014

European Commission. (2010). Action plan on unaccompanied minors (2010-2014). Retrieved November 11, 2016 from http://eurlex.europa.eu/LexUriServ/LexUriServ.do?uri=COM:2010:0213:FIN:en:PDF. 
8 Current Perspectives on Violence Against Children in Europe

European Commission. (2016a). Report from the Commission to the European Parliament and the Council assessing the implementation of the measures referred to in Article 25 of Directive 2011/93/EU of 13 December 2011 on combating the sexual abuse and sexual exploitation of children and child pornography. Retrieved January 18, 2017 from https://ec.europa.eu/homeaffairs/sites/homeaffairs/files/20161216_report_article25_assessing_implementation_ sexual_abuse_child_pornography.pdf.

European Commission. (2016b). Report from the Commission to the European Parliament and the Council assessing the extent to which the Member States have taken the necessary measures in order to comply with Directive 2011/93/EU of 13 December 2011 on combating the sexual abuse and sexual exploitation of children and child pornography. Retrieved January 18, 2017 from https://ec.europa.eu/homeaffairs/sites/homeaffairs/files/20161216_report_extent_member_states_sexual_abuse_ child_pornography_0.pdf.

European Commission. (2016c, November). Protecting child refugees and migrants. Factsheet.

European Commission, Community Research and Development Information Service. (2013). BECAN report summary. Retrieved January 24, 2017 from http://cordis.europa.eu/result/rcn/58856_en.html.

European Network of Ombudspersons for Children. (ENOC, 2015). Position statement on 'violence against children'. Retrieved November 7, 2016 from http://enoc.eu/wpcontent/uploads/2014/12/ENOC-position-statement-on-Violence-against-children2015-FV.pdf. 
Eurostat. (2017). Asylum applicants considered to be unaccompanied minors by citizenship, age and sex Annual data. Retrieved January 28, 2017 from http://appsso.eurostat.ec.europa.eu/nui/show.do?dataset=migr_asyunaa\&lang=en.

Global Initiative to End All Corporal Punishment of Children. (2016). Ending legalised violence against children: Global progress to December 2016. Retrieved February 1, 2017 from www.endcorporalpunishment.org/assets/pdfs/reports-global/Global-report2016.pdf.

House of Lords, European Union Committee. (2016). Children in crisis: Unaccompanied migrant children in the EU. Retrieved January 14, 2017 from www.publications.parliament.uk/pa/ld201617/ldselect/ldeucom/34/34.pdf.

Kloppin, K., Haugland, S., Svedin, C. G., Maehle, M., \& Breivik, K. (2016). Prevalence of child sexual abuse in the Nordic countries: A literature review. Journal of Child Sexual Abuse, 25(1), 37-55. doi:10.1080/10538712.2015.1108944.

Livingstone, S., Mascheroni, G., Ólafsson, K., \& Haddon, L. (2014). Children’s online risks and opportunities: Comparative findings from EU Kids Online and Net Children Go Mobile. London: EU Kids Online, London School of Economics.

Livingstone, S., \& Mason, J. (2015). Sexual rights and sexual risks among youth online: A review of existing knowledge regarding children and young people's developing sexuality in relation to new media environments. London: London School of Economics. Retrieved from http://eprints.lse.ac.uk/64567/1/Livingstone_Review_on_Sexual_rights_and_sexual_r isks_among_online_youth_Author_2015.pdf.

McElvaney, R., \& Lalor, K. (2014). Child abuse in Europe. In J. Conte (Ed.), Child abuse and neglect worldwide (Vol. 2). Santa Barbara, CA: Praeger. 
Menesini, E., Nocentini, A., \& Camodeca, M. (2013). Morality, values, traditional bullying, and cyberbullying in adolescence. British Journal of Developmental Psychology, 31(1), 1-4. doi:10.1111/j.2044-835X.2011.02066.x.

Prevoo, M. J., Stoltenborgh, M., Alink, L., Bakermans-Kranenburg, M., \& Ijzendoorn, M. (2016). Methodological moderators in prevalence studies on child maltreatment: Review of a series of meta-analyses. Child Abuse Review, 26(2), 141-157. doi:10.1002/car.2433.

Personal, Social, Health and Economic education. (PSHE, 2016). Key principles of effective prevention education. London: PSHE Association on behalf of CEOP. Available https://www.pshe-association.org.uk/.../key-principles-effective-prevention-education

Quayle, E., Allegro, S., Hutton, L., Sheath, M., \& Lööf, L. (2012). Online behaviour related to child sexual abuse: Creating a private space in which to offend-Interviews with online child sex offenders. Council of the Baltic Sea States. Stockholm: ROBERT project. Retrieved from http://childcentre.info/robert/.

Quayle, E., Jonsson, L., \& Lööf, L. (2012). Online behaviour related to child sexual abuse: Interviews with affected young people. Council of the Baltic Sea States. Stockholm: ROBERT Project. Retrieved from http://childcentre.info/robert/.

Quayle, E., \& Sinclair, R. (2012). An introduction to the problem. In E. Quayle \& K. M. Ribisl (Eds.), Understanding and preventing online exploitation of children (pp. 322). New York: Routledge.

Save the Children. (2016). 600 children have died in the Mediterranean this year. Retrieved January 12, 2017 from www.savethechildren.net/article/600-children-have-diedmediterranean-year. 
8 Current Perspectives on Violence Against Children in Europe

Sethi, D., Bellis, M., Hughes, K., Gilbert, R., Mitis, F., \& Galea, G. (Eds.) (2013). European report on preventing child maltreatment. Copenhagen: World Health Organization.

Sjursø, I. R., Fandrum, H., \& Roland, R. (2016). Emotional problems in Traditional and Cyber Victimization. Journal of School Violence, 15(1), 114-131. doi:10.1080/15388220.2014.996718.

Stalford, H. (2012). Children and the European Union: Rights, welfare and accountability. Oxford: Hart Publishing.

Townsend, M. (2016, January 30). 10,000 refugee children are missing, says Europol. The Guardian. Retrieved from www.theguardian.com.

UN Committee on the Rights of the Child (CRC). (2016, December 6). General comment No. 20 (2016) on the implementation of the rights of the child during adolescence. CRC/C/GC/20. Retrieved February 13, 2017 from http://tbinternet.ohchr.org/_layouts/treatybodyexternal/Download.aspx?symbolno=CR C/C/GC/20\&Lang=en.

UNHCR. (2016). Mediterranean situation (Operations portal: Refugee situations). Retrieved November 20, 2016 from http://data.unhcr.org/mediterranean/regional.php.

Völlink, T., Dehue, F., \& McGuckin, C. (Eds.). (2016). Cyber bullying: From theory to intervention. New York: Routledge/Taylor \& Francis Group.

Wolak, J., \& Finkelhor, D. (2011). Sexting: A typology. Durham, NH: Crimes Against Children Research Center.

Ziegert, K. (1983). The Swedish prohibition of corporal punishment: A preliminary report. Journal of Marriage and the Family, 45, 917-926. 
8 Current Perspectives on Violence Against Children in Europe

1 Thousands of migrants camped near the Northern French port city of Calais in squalid conditions, often for months at a time, seeking a chance to enter the United Kingdom which is perceived to have greater informal working opportunities. French authorities dismantled the camp in October 2016.

2 http://oireachtasdebates.oireachtas.ie/debates\%20authoring/debateswebpack.nsf/takes/dail2 016102700065 ?opendocument\#WRK03500. 